BMJ Health \& Care Informatics

\title{
Adoption of enterprise architecture for healthcare in AeHIN member countries
}

\author{
Jitendra Jonnagaddala (D , ,,2 Guan N Guo, ${ }^{1,2}$ Sean Batongbacal, ${ }^{3}$ Alvin Marcelo, ${ }^{4}$ \\ Siaw-Teng Liaw ${ }^{1,2}$
}

To cite: Jonnagaddala J, Guo GN, Batongbacal S, et al. Adoption of enterprise architecture for healthcare in AeHIN member countries. BMJ Health Care Inform 2020;27:e100136. doi:10.1136/ bmjhci-2020-100136

- Additional material is published online only. To view please visit the journal online (http://dx.doi.org/10.1136/ bmjhci-2020-100136).

Received 11 February 2020 Revised 17 April 2020 Accepted 01 June 2020

Check for updates

(C) Author(s) (or their employer(s)) 2020. Re-use permitted under CC BY-NC. No commercial re-use. See rights and permissions. Published by BMJ.

${ }^{1}$ School of Public Health and Community Medicine, UNSW Sydney, Sydney, New South Wales, Australia

${ }^{2}$ WHO Collaborating Centre for eHealth, UNSW Sydney, Sydney, New South Wales, Australia

${ }^{3}$ School of Computer Science \& Engineering, UNSW Sydney, Sydney, New South Wales,

Australia

${ }^{4}$ Standards and Interoperability Lab for Asia, University of the Philippines Manila, Manila, Metro Manila, Philippines

Correspondence to Dr Jitendra Jonnagaddala; z3339253@unsw.edu.au

\begin{abstract}
Background Healthcare organisations are undergoing a major transformational shift in the use of information and digital health technologies. Enterprise architecture (EA) has been incrementally adopted in many healthcare organisations globally to facilitate this change. EA can increase the effectiveness of an organisation's digital health capabilities and resources. However, little is known about the status of EA adoption in low-income and middle-income countries. This study aimed to evaluate the challenges, goals and benefits associated with adoption of EA for healthcare in the Asia eHealth Information Network (AeHIN) member countries .
\end{abstract}

Methods We developed an EA Adoption Evaluation framework with four principal layers: governance, strategy, EA and performance. The framework guided the development of a questionnaire to investigate the goals, challenges and benefits faced before and during EA adoption by healthcare organisations.

Sample 26 participants from 18 healthcare organisations in the Asia-Pacific region representing 11 countries. Organisations included Ministries of Health, Universities, Non-Governmental Organisations and Technical Advisory Groups.

Findings Only 5 of the 18 organisations had begun adopting EA. The goals expressed for EA adoption were to address issues such as interoperability, lack of technical infrastructure and poor alignment of business and information technology strategies. Cost reduction was less emphasised. The main challenges to adopting EA was the lack of EA knowledge, leadership and involvement of senior management.

Conclusion The adoption of EA is incipient in AeHIN member healthcare organisations. To encourage EA adoption, these organisations need to invest in internal capacity building, senior management training and seek independent EA expert advice to systematically identify and address the barriers to adopting EA.

\section{INTRODUCTION}

Healthcare is currently experiencing a major transformation in its use of information and digital health technologies. ${ }^{1}$ Many organisations are increasingly adopting more information technology (IT) systems to assist in providing care. However, these organisations are facing issues such as standardisation, integration and alignment with the business strategy. Enterprise architecture (EA) is a
Summary

What is already known?

- Healthcare organisations are facing business strategy alignment and interoperability issues as they move towards the adoption of digital health resources and systems.

- Enterprise architecture (EA) is a conceptual paradigm, healthcare organisations can leverage to address these critical issues systematically.

- In the last decade healthcare organisations have started to evaluate and adopt EA, majority with a final objective of improvement in patient care.

- Asia eHealth Information Network (AeHIN) is a collaborative network of individuals and country representatives from the Asia-Pacific region committed to the use of IT to strengthen healthcare and health systems.

What does this paper add?

- Our findings highlight that adoption of EA in healthcare organisations is still in very early stages in the AeHIN member countries.

- We identified that the key driver for adopting EA in healthcare organisations is to address interoperability issues in the digital health era.

- Lack of senior management experience and involvement in EA is a major challenge for the adoption of EA in these countries.

blueprint-a coherent framework of principles, methods and models-used in the design and realisation of the enterprise's organisational structure, business process, information systems and digital health infrastructure. ${ }^{2}$ EA is also commonly described as a master plan providing a holistic view of the entire enterprise as a system of systems. $^{2}{ }^{3}$ Its implementation provides several benefits to organisations. ${ }^{4}$ It primarily addresses complexity management, allowing for standardisation and consolidation of the organisational units and components holistically. Removing complexity from the organisation's overall architecture is the paramount benefit of EA. It also provides transparency to the organisation by simplifying the organisational structure and internal interactions. 


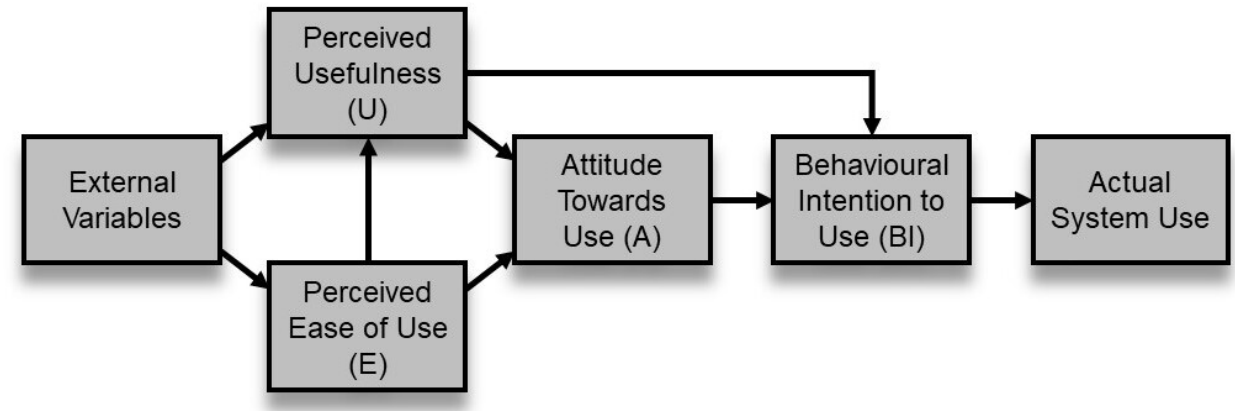

Figure 1 Technology Acceptance Model (TAM).

This, in turn, can assist management in making better and more informed decisions. This allows for improved business and IT alignment by ensuring that business requirements and IT implementation are appropriately matched. A mismatch between business requirements and IT implementation can result in compounded difficulties. ${ }^{5}$ Improved transparency and reduced complexities can optimise operations and help reduce IT and business-related costs.

Many healthcare organisations that have adopted EA have experienced several benefits. ${ }^{6}$ There are many different approaches to implementing EA. A common approach is to reuse an existing EA framework. Some well-known EA frameworks include The Open Group Architecture Framework, ${ }^{7}$ Zachman $^{8}$ and federal enterprise architecture framework. ${ }^{9}$ EA implementation involves creating a coherent and structured model of the enterprise, which systematically documents the structures within the enterprise and their dependencies. ${ }^{10}$ This complex task is performed by employing architectural layers and views to describe and present the organisation at different levels and from the perspectives of different stakeholders. ${ }^{4}$

Successful implementation of EA requires both adoption and evaluation frameworks. ${ }^{11} 12$ One such framework is the Technology Acceptance Model (TAM) framework (figure 1) .TAM presents how users accept a new technology using perceived usefulness, perceived ease of use, attitude towards using, intent to use, actual use and external variables. ${ }^{13}$ Generally, TAM has been used to judge the acceptance and use of new technologies such as the adoption of handheld computers in healthcare. ${ }^{14}$ For example, TAM has been used to develop a questionnaire to evaluate the adoption of technology. ${ }^{15}$ TAM can be used across various domains ${ }^{16}$ but may require modification for better applicability in the healthcare context. ${ }^{17} \mathrm{In}$ the context of EA, TAM has been used as both adoption (to assist with implementation of EA) and evaluation (to assess the planned or preplanned implementation of EA) frameworks. ${ }^{18}$

Previous studies on EA in healthcare have mostly evaluated the EA implementation framework used; a few studies examined the overall adoption of EA by organisations. ${ }^{451920}$ Frameworks have been developed to specifically analyse EA adoption, content and governance. ${ }^{21}$
The framework developed by Janssen and Hjort-Madsen ${ }^{3}$ to evaluate EA in governments used five aspects: policies, actors and structures; governance; architecture frameworks and methodologies; architecture principles and standards; implementations. Liimatainen $e t a l^{22}$ extended this framework with two additional aspects: benefits and evaluation. This suggested a possible approach to evaluate EA adoption concerning its constituent aspects. The United States General Accounting Office ${ }^{23}$ evaluated the adoption of EA using the EA Maturity Model. ${ }^{18}$ Hjort-Madsen and Pries-Heje ${ }^{24}$ studied the adoption of EA in government regarding the reasons and effects of adoption. ${ }^{19}$ In another study, Lange and Mendling investigated the goals and benefits of EA adoption Lange and Mendling. ${ }^{4}$

Although there are many studies related to EA adoption in other sectors there is little evidence on evaluation of EA adoption in healthcare organisations. On top of that, the existing evidence fails to discuss the benefits, challenges and primary goals associated with the adoption of EA for healthcare in in low-income and middle-income countries (LMICs). With this in mind, we aimed to systematically investigate factors associated with the adoption of EA in LMICs healthcare organisations in the Asia-Pacific region through the Asia eHealth Information Network (AeHIN) . AeHIN is a collaborative network of individuals and country representatives from the Asia-Pacific region committed to the use of IT to strengthen healthcare and health. ${ }^{25}$ AeHIN has over 30 member countries, primarily consisting of LMICs in the Asia-pacific region. We developed a robust evaluation framework to investigate the key aspects associated with EA adoption based on the TAM framework. As per our knowledge, TAM has not been previously applied to EA for healthcare organisations. The developed framework is used to design a structured questionnaire to collect the data.

\section{METHODS}

\section{Development of EAAE framework}

We have used the TAM framework to devise the EA Adoption Evaluation (EAAE) framework. The TAM framework assisted us to focus not only on the perceived usefulness and performance of EA but also on perceived ease of EA use, attitude towards EA and intent to use EA in the 
context of a healthcare organisation. Although the TAM framework can be directly used to develop an evaluation strategy, it might not be flexible and reusable without an intermediate framework such as the EAAE framework. Unlike many other studies, ${ }^{26}{ }^{27}$ wherein the TAM framework was used to quantitatively assess the usability, we have only used it as a basis to develop a generic evaluation framework because EA adoption is multifactorial and often complex covering several components beyond the TAM framework components. Similar approach of using the TAM framework as a basis and developing a more robust framework has been demonstrated in other studies. ${ }^{28-31}$

The EAAE framework was developed systematically in an iterative manner. We determined the components to be evaluated in the EA adoption based on existing literature. We focused on EA adoption studies in the healthcare sector to identify relevant components. The components identified through this process were then devised into a logical framework. All the authors have iteratively revised the framework based on feasibility, usability and suitability. Feedback on the EAAE framework and questionnaire was also obtained from the relevant stakeholders at the AeHIN Workshop held in Nanjing, China in 2016. This resulted in improvements, such as refining inadequately covered components or eliminating overlapping components. Finally, the components of the TAM framework were compared with the EAAE framework to ensure that it appropriately accounted for the issues covered by the TAM framework.

\section{Questionnaire design and study setting}

A questionnaire developed using the approach explained in the previous section was used for data collection. Table 1 illustrates how the items in the questionnaire align with TAM and EAAE frameworks. The questionnaire collected responses in the form of Likert scale-based ratings and open-ended responses, where applicable, to explore the rationale behind the participants' responses. ${ }^{32} \mathrm{We}$ recruited the participants through the AeHIN at the AeHIN general meeting in Myanmar in 2017. First, participants were briefed about the study and consent was obtained from the eligible participants. The key eligibility criteria was, participants need to be digital health decision-makers in their organisations who are familiar with EA. Where necessary, individual respondents were followed up to seek clarity on their responses or obtain additional comments. This was followed by analysis and triangulation of data to deduce key findings. Please refer to the online supplementary appendix A for additional information on the methods and materials employed as part of this study.

\section{Data analysis}

The data collected was systematically analysed and summarised to highlight the challenges associated with the EA adoption in healthcare organisations in the Asia-Pacific region. The participants' responses were subjected to data quality checks and any erratic responses were omitted. The open-ended text responses were analysed thematically using the NVivo V.12 Pro software. Key themes were identified independently by two authors by verifying the participants' responses. This was followed by characterisation of participant demographics. Due to the small sample size, the analyses were primarily performed for the overall data. Participants were then subjected to subgroup analysis to understand the heterogeneity of organisations they represent. Finally, we summarised the EA adoption challenges by triangulating the data with participant characteristics.

\section{RESULTS \\ EAAE framework}

The framework consisted of four main layers, each of which contained several components (figure 2). The

Table 1 Integration of EAAE and TAM framework components into the questionnaire

TAM framework components

\begin{tabular}{|c|c|c|c|c|}
\hline $\begin{array}{l}\text { External } \\
\text { variables }\end{array}$ & $\begin{array}{l}\text { Perceived } \\
\text { usefulness }\end{array}$ & Perceived ease of use & $\begin{array}{l}\text { Attitude towards } \\
\text { usage }\end{array}$ & Intention to use \\
\hline
\end{tabular}

EAAE framework components

\begin{tabular}{|c|c|c|c|c|c|}
\hline Governance & & 9,10 & 9,10 & 11 & \\
\hline Business strategy & & 3,4 & 3,5 & 5 & 5,6 \\
\hline Adherence & & 17 & 17 & 18 & 18 \\
\hline Performance & & 14,15 & & 16 & 16 \\
\hline Objectives & & 1 & 1 & 2 & 2 \\
\hline Architecture & 12 & 12 & 12 & 12 & 12 \\
\hline IT strategy & & 8 & 8 & 8 & 8 \\
\hline Interoperability & 13 & 13 & 13 & 13 & 13 \\
\hline
\end{tabular}

Each cell in the table refers to question number in the questionnaire. Please refer to the online supplementary appendix 2 for individual questions.

EAAE, EA Adoption Evaluation; IT, information technology; TAM, Technology Acceptance Model. 


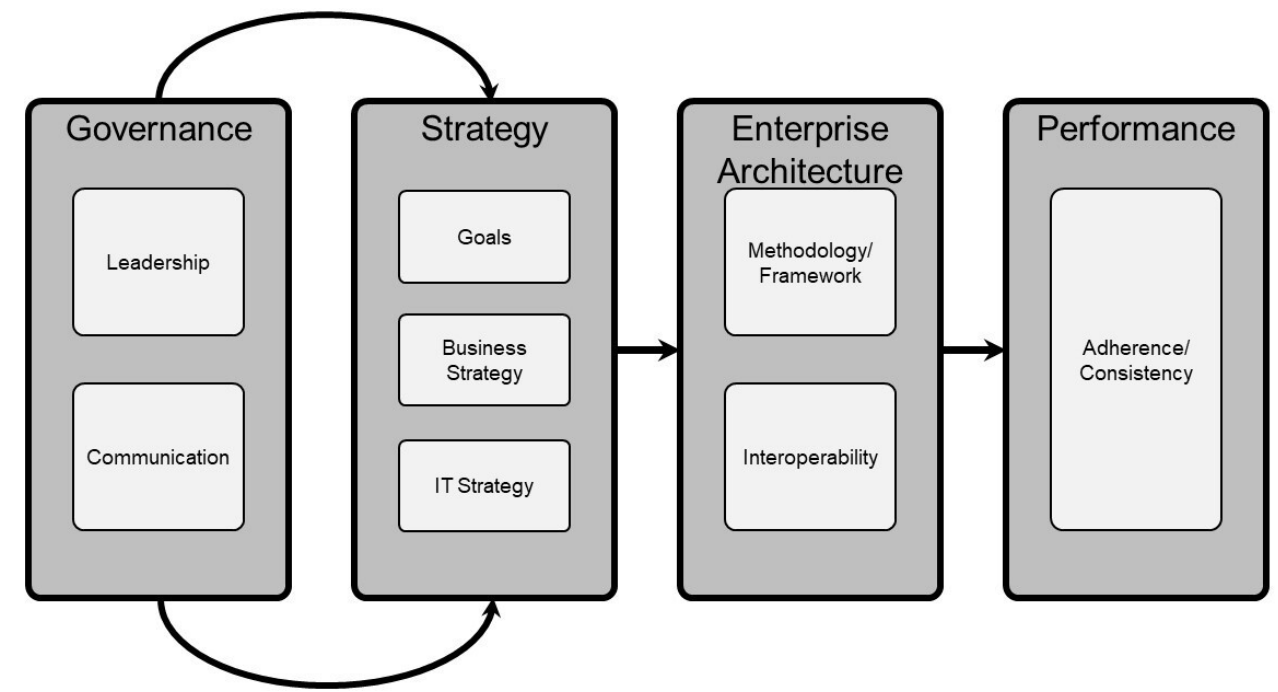

Figure 2 EAAE evaluation framework. EAAE, EA Adoption Evaluation; IT, information technology.

governance layer and its components of leadership and communication encompassed an organisation's governance; how the organisation is led and controlled. The strategy layer and its component goals, business and IT strategy encompassed the organisation's strategy. The EA layer encompassed the organisation's EA, their methodology/framework, and its interoperability. Finally, the performance layer encompassed the organisation's performance regarding their EA and the adherence to their EA throughout the organisation. Additionally, the arrows in the framework demonstrate the relations and interactions between each layer. Specifically, governance and strategy affect each other, while strategy dictates the EA, which eventually dictates the performance. These connections can be used to further analyse an organisation's EA adoption by assisting in determining the factors influencing and influenced by an area of interest. Each layer of the framework represents a major factor associated with EA adoption, and each component represents additional factors of specific importance within the layers. By analysing and addressing each of these layers and components, a multifaceted view and evaluation of the state of EA adoption can be made.

To use the EAAE framework, each layer of the framework and their components must be analysed while considering the relations between layers when appropriate. This analysis could be performed by creating surveys or interviews with questions intended to address and evaluate each layer and component described by the framework and using these surveys or interviews with appropriate individuals who would be able provide sufficient detail, such as senior managers or enterprise architects. ${ }^{33}$ These results may then be combined and analysed together with any other evaluation of the state of EA adoption in the organisation. We recommend that the framework be used and employed by an independent expert familiar with EA and strategy to avoid bias. It may also be utilised by internal enterprise architects and executives. Our framework should be used when there are expectations of critical or radical changes to a healthcare organisation, such as large growth or funding changes and those who are planning to or have adopted EA. A better understanding of the situation of the organisation(s) can be obtained by using this framework to evaluate EA adoption, thus enabling better decision-making regarding the expected changes. This framework provides a holistic view of major factors influencing EA adoption at various layers. This allows identification of areas of interest about the state of EA adoption for a given organisation, such as components that had a positive or negative effect.

\section{Participant characteristics}

This study included a total of 26 participants(table 2). Four participants who did not complete the survey and another four who were not familiar with EA were excluded from the analysis. The remaining 18 participants' responses were analysed. Participating organisations were from 11 different countries in the Asia-Pacific, most of which were low to middle-income developing countries. One Australian organisation was an exception. We identified 13 organisations who were in the process of adopting or had already adopted EA. The participants were mostly male $(61.1 \%)$ aged $41-60$ years, with an experience of more than 10 years in healthcare. Nine participants had an experience of more than 20 years. Half of the participants were from large organisations with more than 10000 employees. Most (66.6\%) of the participants came from the Ministry of Health $(\mathrm{MoH})$, while others came from a range of organisations such as University, Non-Governmental Organisation, Consultancy or technical advisor group. Most participants were familiar with $\mathrm{EA}$, and some were also professionally trained in EA. The TOGAF (1GovEA based on TOGAF) model was the most widely used EA framework. Only one participant has implemented all the four layers of TOGAF, namely business, data, application and technology. Others used either just business, or application and data, or business, data and application layers. In other words, only 1 participant 
Table 2 Participant characteristics and status of EA adoption

\begin{tabular}{|lcr}
\hline Category & $\begin{array}{l}\text { Number of } \\
\text { participants }\end{array}$ & $\begin{array}{l}\text { Percentage of } \\
\text { participants }\end{array}$ \\
\hline Country & & \\
\hline Australia & 2 & 11.1 \\
\hline Cambodia & 2 & 11.1 \\
\hline Vietnam & 1 & 5.6 \\
\hline India & 2 & 11.1 \\
\hline Indonesia & 1 & 5.6 \\
\hline Laos & 1 & 5.6 \\
\hline Malaysia & 5 & 27.8 \\
\hline Mongolia & 1 & 5.6 \\
\hline Myanmar & 1 & 5.6 \\
\hline Sri Lanka & 1 & 5.6 \\
\hline Thailand & 1 & 5.6 \\
\hline Age & & \\
\hline$<40$ & 3 & 16.7 \\
\hline $41-50$ & 7 & 38.8 \\
\hline $51-60$ & 5 & 27.8 \\
\hline 61 or older & 3 & 16.7 \\
\hline Gender & & \\
\hline Male & 11 & 61.1 \\
\hline Female & 7 & 38.8 \\
\hline Experience in years & & 11.1 \\
\hline $0-5$ & 2 & 44.4 \\
\hline $5-10$ & 2 & 33.3 \\
\hline 10-20 & 8 & \\
\hline Over 20 & 6 & \\
\hline
\end{tabular}

Type of organisation

\begin{tabular}{lrr} 
MoH & 12 & 66.6 \\
\hline University & 3 & 16.7 \\
\hline NGO & 2 & 11.1 \\
\hline Technical Advisor & 1 & 5.6 \\
\hline
\end{tabular}

Number of employees in the organisation

\begin{tabular}{|lrr|}
\hline $0-50$ & 3 & 16.7 \\
\hline $51-200$ & 3 & 16.7 \\
\hline $201-1000$ & 2 & 11.1 \\
\hline $1001-5000$ & 1 & 5.6 \\
\hline $5001-10000$ & 1 & 5.6 \\
\hline More than 10 000 & 8 & 44.4 \\
\hline $\begin{array}{l}\text { Highest educational } \\
\text { qualification }\end{array}$ & \\
\hline Diploma & 1 & 4.5 \\
\hline Bachelors & 13 & 59.1 \\
\hline Masters & 3 & 13.6 \\
\hline Doctoral & 5 & 22.7 \\
\hline
\end{tabular}

Continued
Table 2 Continued

\begin{tabular}{lll}
\hline Category & $\begin{array}{l}\text { Number of } \\
\text { participants }\end{array}$ & $\begin{array}{l}\text { Percentage of } \\
\text { participants }\end{array}$ \\
\hline $\begin{array}{l}\text { Status of EA adoption } \\
\text { Not adopted/plan to } \\
\text { adopt EA }\end{array}$ & 14 & 77.8 \\
$\begin{array}{l}\text { Adopting EA } \\
\begin{array}{l}\text { EA framework (planned/ } \\
\text { In use) }\end{array}\end{array}$ & 4 & 22.2 \\
$\begin{array}{l}\text { TOGAF/1GovEA } \\
\text { Others }\end{array}$ & 6 & 33.3 \\
$\begin{array}{l}\text { Unknown/not yet } \\
\text { decided }\end{array}$ & 4 & 22.2 \\
\hline
\end{tabular}

EA, enterprise architecture; $\mathrm{MoH}$, Ministry of Health; TOGAF, The Open Group Architecture Framework.

had fully adopted EA, 14 participants were planning to adopt EA and 4 were in the process of adopting EA. Since most of the participants had not yet adopted EA, the postadoption responses such as the benefits and challenges were analysed based on perceived usefulness and perceived ease of use components from TAM framework.

\section{Primary goals for adopting EA}

The questionnaire assessed the EA preadoption phase covering the objectives, goals, vision and mission of EA. The objectives presented by the respondents were consistent, with the major goals for EA adoption being to achieve (1) interoperability through standardisation, consolidation and effective management of complexities; (2) governance and (3) business and IT strategy alignment (table 3). Other goals, including cost reduction, agility, innovation, transparency and regulatory compliance, were also deemed as important. Business process re-engineering and support to the health system reform were the two other goals identified.

\section{Challenges to EA adoption}

Participants reported that before EA adoption, there were issues with their business and IT alignment, interoperability, governance, standardisation, ownership and knowledge. Interoperability was also identified as a very important factor across all organisations. Sixteen participants also reported that interoperability affected their decision to adopt EA. Throughout our thematic analysis, funding, interoperability and lack of EA awareness were consistently identified as the key difficulties faced by the organisations before adoption.

Participants identified the lack of EA experience in the leadership as the key challenge during the EA adoption process. This is consistent with existing perceptions that the adoption of EA is particularly difficult in organisations where the senior management does not have adequate experience with EA. Participants strongly felt a need for effective communication between the senior management and EA implementers for successful adoption and 
Table 3 Primary goals for adopting EA

\begin{tabular}{lcc}
\hline Goals & Number of participants & Percentage of participants \\
\hline Business and IT strategy alignment & 13 & 16.5 \\
Cost reduction & 9 & 11.4 \\
Interoperability/standardisation & 16 & 20.3 \\
Governance & 14 & 17.7 \\
Agility & 5 & 6.3 \\
Innovation & 7 & 8.9 \\
Transparency & 8 & 10.1 \\
Regulatory compliance & 7 & 8.9 \\
\hline
\end{tabular}

EA, enterprise architecture; IT, information technology.

implementation. Half of the participants said they were willing to hire external EA experts to address this issue. However, they would also like to use any free resources that can assist with EA adoption.

\section{Benefits of EA}

Since most of the participants did not adopt EA in their organisations, their perceived benefits of EA adoption were analysed instead of benefits observed. All participants concurred that EA would have a positive effect on their organisation. Among these participants, the interoperability aspect was perceived as the most significant benefit of EA, followed by reliability and security. Nearly all the participants also agreed that EA adoption had or will have a positive impact on the business strategy. However, when asked specifically about infrastructure, the opinions were mixed. Seven participants responded that EA would not improve infrastructure regarding reliability, maturity or scalability, while eight responded that it would improve. Among those who had begun EA adoption, all participants reported a positive effect on their organisation. They also noted improvements in the management and utilisation of IT infrastructure. Please refer to the online supplementary appendix A for additional results.

\section{DISCUSSION}

Our findings highlighted the primary goals for EA adoption and revealed the difficulties and benefits before and after EA adoption by healthcare organisations in the AeHIN. The relevance of the primary goals of EA will be a major determinant of the successful adoption of EA by the organisations. Sharing these goals widely will provide a holistic view of the rationale behind EA adoption across the healthcare system.

Most of the reported primary goals for EA adoption were consistent with those expressed in previous studies. ${ }^{44}$ For example, EA's core defining features like the business and IT strategy alignment and complexity management remained consistent with previous findings. However, unlike these previous studies, we found that transparency and cost reduction were not prioritised as being more important than other goals such as interoperability. ${ }^{4}$ There are a few possible explanations for this observation. It could demonstrate a paradigm shift in EA goals in public healthcare organisations as compared with private organisations, which were often studied in previous studies. ${ }^{35}$ It is more likely to demonstrate a more mature understanding of EA as a mechanism for safety and quality of healthcare as opposed to a mistaken view that EA is a means to reduce costs.

The participants identified interoperability as a key challenge in their organisation before adopting EA. The primary goals discussed previously also echo the same finding. Interoperability is a key issue for healthcare organisations. ${ }^{36}$ Although this is not a new finding and has been well documented, we can infer from our study results that interoperability remains a major challenge in both developing and developed countries' healthcare systems. As organisations adopt more health information systems, both internal and external interoperability issues arise. With maturity in healthcare standards and regulation of vendors supplying health information systems, most of these systems are now capable of interoperating internally to some extent. However, organisations still suffer from a lack of seamless standardisation and communication between these information systems internally. External interoperability allows the exchange of data and information with other organisations. The need for information exchange drives external interoperability demand. ${ }^{1937}$ However, external interoperability remains a major issue due to lack of economic or political incentives in the healthcare sector, both in developed and developing countries. Our thematic analysis of the responses also identified external interoperability as a major issue. Government healthcare organisations in the AeHIN countries are also reluctant to exchange information due to issues such as lack of appropriate standards, privacy concerns, policies and legislation.

We also discovered many non-technical challenges related to EA adoption. Leadership and communication appeared as one of the key challenges for EA adoption in our study. Leadership is a key factor in EA adoption as it provides direction and management foundation required for successful EA adoption. ${ }^{38}$ Most of our participants 
believed that senior management demonstrated very little knowledge or experience in EA. This is an important issue which can be addressed in the short-term through appropriate training and providing additional resources and support to the senior management. This, in turn, can improve engagement among all the stakeholders in EA adoption. We found that half of the organisations were not willing to hire external consultants due to costs. Another issue is that there are communication gaps between the senior management and the employees implementing EA. Continuous communication between all stakeholders is vital for the successful development and adoption of EA. ${ }^{39}$ The lack of communication would make the adoption process more difficult and less efficient. In an earlier study, the lack of soft skills, such as people skills and leadership skills among practitioners has been attributed to poor communication during EA adoption. ${ }^{40}$ Our thematic analysis also confirmed that $30 \%$ of our participants, who are mostly senior management, have experienced similar issues with EA practitioners. We also presented the benefits of adopting EA. The adoption is perceived to have positive effects on the organisations. While there have been improvements in IT infrastructure and business and IT strategy alignment among those implemented, it has been reported that EA benefits are difficult to achieve and measure in short-term. ${ }^{41} 42$

Overall, our findings show a very incipient and superficial application of EA for healthcare within the AeHIN member countries. Only a handful of organisations have begun the adoption while most are yet to start the adoption process. Most of the participants are from $\mathrm{MoH}$ or equivalent government bodies, who perceive the EA benefits. However, these organisations' internal capability maturity appears to be a huge limiting factor. It is recommended that besides building internal capacity for EA in health organisations, they should also consider knowledge exchange with other organisations in the Asia-pacific region. Also explore the option of obtaining expert EA services from certified EA consultants with experience and understanding of the local health systems and organisations. The investment on the foundational blueprint will easily outweigh the costs and risks of trying to implement a poorly architected public healthcare system. ${ }^{26}$

This study is subjected to several limitations. The EAAE framework proposed in this study assumed that EA could be considered as a technology to which the TAM framework could be applied. The EAAE framework assumed that all the major steps of the EA implementation lifecycle were captured and was an adequate representation of the lifecycle for this framework. The framework was targeted towards senior management at healthcare organisations (ie, any evaluation to be undertaken using this framework requires seeking information from the senior management). Future work could include data collection from other members of the organisation and consumers/ customers, in this case, patients. Additionally, the EAAE framework assumed that certain factors were critical for healthcare organisations. These include sensitive patient information and external influences, such as regulators, legislations and compliance. It was also assumed that participants were familiar with their healthcare organisation's business and IT strategy, and had functional knowledge of IT usage in their organisations. It is also important to note that most of the participants have not fully implemented EA, and their responses were based on perceived usefulness. The results from this study should also be interpreted in the context of IT usage in low resource health systems as reported by a limited number of participants from a selective AeHIN countries. AeHIN though is a very good representative sample for LMICs in the region but does not cover all the Asia-Pacific countries. In other words, the findings in this study might not apply to the Asia-Pacific region which includes several high-income countries too. The limited sample size with reduced statistical power in this study does not allow to draw any firm conclusions.

\section{CONCLUSION}

We developed the EAAE framework to assess the adoption of EA in healthcare organisations. This generic framework guided the development of an instrument to assess EA adoption in 18 Asia-Pacific healthcare organisations across 11 different countries. Most organisations reported challenges with interoperability, technical infrastructure and alignment of business and IT strategies. These challenges determined the primary goals of these organisations for adopting EA. Cost reduction was less emphasised as an EA adoption goal. All organisations believed that their interoperability and infrastructure would improve after adopting EA. Lack of EA knowledge and leadership among senior management is a major issue that needs to be addressed for a successful EA adoption. This study highlights the need for capacity building in the areas of EA implementation, adoption and evaluation targeted towards the senior management in the first instance. This study is subjected to several limitations such as small sample size with reduced statistical power resulting in preliminary findings. However, the study identified high-level challenges in the regions that require further investigation.

\section{Twitter Siaw-Teng Liaw @EIAstee}

Acknowledgements We would like to acknowledge the study participants, Asian eHealth Information Network (AeHIN) for support and Diane Bool for assistance with the preliminary analyses. This study was conducted as part of the WHO Collaborating Centre on eHealth and the UNSW Electronic Practice Based Research Network (ePBRN) research program. The ePBRN is supported by the UNSW School of Public Health \& Community Medicine and Centre for Primary Health Care \& Equity, and the Ingham Institute of Applied Medical Research.

Contributors JJ conceived and designed the study, conducted the survey, analysed and interpreted the data and wrote the manuscript. GNG analysed and interpreted the data and wrote the manuscript. SB undertook literature review and wrote the manuscript. AM and STL supervised and were responsible for the funding.

Funding The authors have not declared a specific grant for this research from any funding agency in the public, commercial or not-for-profit sectors.

Competing interests None declared. 
Patient consent for publication Not required.

Provenance and peer review Not commissioned; externally peer reviewed.

Data availability statement Data are available upon reasonable request.

Open access This is an open access article distributed in accordance with the Creative Commons Attribution Non Commercial (CC BY-NC 4.0) license, which permits others to distribute, remix, adapt, build upon this work non-commercially, and license their derivative works on different terms, provided the original work is properly cited, appropriate credit is given, any changes made indicated, and the use is non-commercial. See: http://creativecommons.org/licenses/by-nc/4.0/.

\section{ORCID iD}

Jitendra Jonnagaddala http://orcid.org/0000-0002-9912-2344

\section{REFERENCES}

1 Wilson EV, Lankton NK. Interdisciplinary research and publication opportunites in information systems and health care. Communications of the Association for Information Systems 2004;14:51.

2 Jonkers H, Lankhorst MM, ter Doest HWL, et al. Enterprise architecture: management tool and blueprint for the organisation. Inf Syst Front 2006;8:63-6

3 Janssen M, Hjort-Madsen K. Analyzing enterprise architecture in national governments: the cases of Denmark and the Netherlands. System Sciences, 2007. HICSS 2007. 40th Annual Hawail International Conference on, 2007.

4 Lange M, Mendling J. An experts' perspective on enterprise architecture goals, framework adoption and benefit assessment. Enterprise Distributed Object Computing Conference Workshops (EDOCW), 2011 15th IEEE International, 2011.

5 Tang A, Han J, Chen P. A comparative analysis of architecture frameworks. Software Engineering Conference, 2004, Asia-Pacific, 2004.

6 Bradley RV, Pratt RME, Byrd TA, et al. Enterprise architecture, it effectiveness and the mediating role of it alignment in US hospitals. Inf Syst J 2012;22:97-127.

7 Josey A. An introduction to the TOGAF standard, version 9.2, 2018.

8 Zachman JA. A framework for information systems architecture. IBM Systems Journal 1987;26:276-92.

9 Federal Chief Information Officers Council. Federal enterprise architecture framework version 1.1, 1999.

10 Winter R, Fischer R. Essential layers, artifacts, and dependencies of enterprise architecture. Enterprise Distributed Object Computing Conference Workshops, 2006. EDOCW'06. 10th IEEE International, 2006.

11 Nikpay F, Ahmad R, Yin Kia C. A hybrid method for evaluating enterprise architecture implementation. Eval Program Plann 2017;60:1-16.

12 Lange M, Mendling J. An experts' perspective on enterprise architecture goals, framework adoption and benefit assessment. 2011 IEEE 15th International Enterprise Distributed Object Computing Conference Workshops, 2011.

13 Davis FD. A technology acceptance model for empirically testing new end-user information systems: theory and results. Massachusetts Institute of Technology, 1985.

14 Lu Y-C, Xiao Y, Sears A, et al. A review and a framework of handheld computer adoption in healthcare. Int J Med Inform 2005;74:409-22.

15 Gao S, Krogstie J, Siau K. Developing an instrument to measure the adoption of mobile services. Mobile Information Systems 2011;7:45-67.

16 Alharbi S, Drew S. Using the technology acceptance model in understanding academics' behavioural intention to use learning management systems. IJACSA 2014;5:143-55.

17 Holden RJ, Karsh B-T. The technology acceptance model: its past and its future in health care. J Biomed Inform 2010;43:159-72.

18 Bernaert Met al. Enterprise Architecture for Small and Medium-Sized Enterprises: A Starting Point for Bringing EA to SMEs, Based on
Adoption Models. In: Devos J, van Landeghem H, Deschoolmeester $\mathrm{D}$, et al, eds. Information systems for small and medium-sized Enterprises: state of art of is research in SMEs. Berlin, Heidelberg: Springer Berlin Heidelberg, 2014: 67-96.

19 Hjort-Madsen K. Institutional patterns of enterprise architecture adoption in government. Transforming Government: People, Process and Policy 2007;1:333-49.

20 Urbaczewski L, Mrdalj S. A comparison of enterprise architecture frameworks. Issues in Information Systems 2006;7:18-23.

21 Aziz Set al. Enterprise architecture: a governance framework, 2005.

22 Liimatainen K, Hoffmann M, Heikkilä J. Overview of enterprise architecture work in 15 countries. Ministry of finance, state it management unit, research reports 6B, 2007.

23 United States General Accounting Office. Enterprise architecture use across the federal government can be improved. Report to Congressional Committees, 2002.

24 Hjort-Madsen K, Pries-Heje J. Enterprise architecture in government FAD or future? System Sciences, 2009. HICSS'09. 42nd Hawail International Conference on, 2009.

25 Marcelo PGF, Evangelista AL, Orjalo CS. Webinars as a knowledge sharing platform for ehealth in South and Southeast Asia. Journal of the International Society for Telemedicine and eHealth 2016;4:1-16.

26 Higman S, Dwivedi V, Nsaghurwe A, et al. Designing interoperable health information systems using enterprise architecture approach in resource-limited countries: a literature review. Int $J$ Health Plann Manage 2019;34:e85-99.

27 Ahadzadeh AS, Sharif SP, Ong FS. Online health information seeking among women: the Moderating role of health consciousness, 2018.

28 Ramkumar M, Schoenherr T, Wagner SM, et al. Q-TAM: A quality technology acceptance model for predicting organizational buyers' continuance intentions for e-procurement services. Int J Prod Econ 2019;216:333-48.

29 Al-Somali SA, Baghabra H. Investigating the determinants of it professionals' intention to use cloud-based applications and solutions: an extension of the technology acceptance. Cloud Security: Concepts, Methodologies, Tools, and Applications, 2019:2039-58.

30 Monkman H, Kushniruk AW. The consumer health information system adoption model. Stud Health Technol Inform 2015;218:26-31.

31 Sahin C. Rules of engagement in mobile health: what does mobile health bring to research and theory? Contemp Nurse 2018:54:374-87.

32 Bandara Wet al. Major issues in business process management: an expert perspective, 2007.

33 Pinsonneault A, Kraemer K. Survey research methodology in management information systems: an assessment. J Manag Inf Syst 1993:10:75-105.

34 Schöenherr M. Towards a common terminology in the discipline of enterprise architecture. International Conference on Service-Oriented Computing, Springer, 2008.

35 Lan Z, Rainey HG. Goals, rules, and effectiveness in public, private, and hybrid organizations: more evidence on frequent assertions about differences. J Public Adm Res Theory 1992;2:5-28.

36 Ducq Y, Chen D, Vallespir B. Interoperability in enterprise modelling: requirements and roadmap. Adv Eng Inform 2004;18:193-203.

37 Hjort-Madsen K. Enterprise architecture implementation and management: a case study on interoperability. System Sciences, 2006. HICSS'06. Proceedings of the 39th Annual Hawaii International Conference on, 2006.

38 General Accounting Office (GAO). Leadership remains key to agencies making progress on enterprise architecture efforts, 2003.

39 Lankhorst M. Enterprise architecture at work: modelling, communication and analysis. Springer, 2009.

40 Chuang $\mathrm{C}-\mathrm{H}$, van Loggerenberg J. Challenges facing enterprise architects: a South African perspective. System Sciences (HICSS), 2010 43rd Hawaii International Conference on, 2010.

41 Grembergen Wv, Saull R. Aligning business and information technology through the balanced Scorecard at a major Canadian financial group: it. in hicss. IEEE, 2001.

42 Niemi E. Enterprise architecture benefits: perceptions from literature and practice. Tietotekniikan tutkimusinstituutin julkaisuja 2008;18:1236-615. 